\title{
Evaluation of Microbial Community Composition of Dairy Sewage Sludge, Corn Silage, Grass Straw, and Fruit Waste Biomass for Potential Use in Biogas Production or Soil Enrichment
}

\author{
Karolina Oszust * and Magdalena Frąc
}

\begin{abstract}
The purpose of the study was to link microbial community composition and chemical properties of various biomass and their resulting digestate residues for their potential use in biogas production or soil enrichment. The order of biogas production, graded from high to low was as follows: corn silage, grass silage, fruit waste, and dairy sewage sludge. Different bacterial families were predominant in different biomass. Corn silage deteriorated as a result of longterm air exposition and may serve as an efficient feedstock substrate for anaerobic digestion. A positive role in plant biocontrol microorganisms found in grass straw residues, and reasonable biogas yield obtained from this substrate suggests the use of grass straw for biogas production and its residues to enrich the soil. Due to potential threat of introducing pathogens into the soil within fruit waste or dairy sewage sludge, or soil acidification by fruit waste repeated use in field application, this biomass should be sanitized prior to soil application. Simultaneously, low biogas yields from fruit waste and dairy sewage sludge substrates make it necessary to transform them in anaerobic digestion with more energetic co-substrates. Tested residues may deliver a robust and wide range of methanogens as inoculum for further anaerobic digestion process.
\end{abstract}

Keywords: Methane fermentation; Microbial biodiversity; Fruit waste; Dairy sewage sludge; Silage; NGS

Contact information: Institute of Agrophysics, Polish Academy of Sciences, Doświadczalna 4, 20-290 Lublin, Poland; *Corresponding author: k.oszust@ipan.lublin.pl

\section{INTRODUCTION}

In recent years, the use of biomass for various management, such as biogas production or soil enrichment, has received increasing attention and is regarded as a simple commodity that has a value. Since biomass processing is microbially mediated and microorganisms quickly react to the changes occurring in environments, microbial community composition can provide evidence of how biodegradation is proceeding.

Accordingly, as methane is produced by the activity of several microorganisms, gaining knowledge about the ecophysiology of the microbes enhances the understanding of their particular roles (Goswami et al. 2016). Methanogenesis is the key step for methane production (Schink et al. 2017), but the microbiologically controlled hydrolysis of complex macromolecules can be regarded as the rate-limiting step of plant biomass bioconversion (Veeken and Hamelers 1999). These aspects drive the need for in-depth knowledge of the microbial community composition of feedstock substrates. It is also necessary to analyse and control the quality of the physicochemical properties and the microbiological composition of these substrates (Insam et al. 2015). At present, the application of high-throughput sequencing technologies (NGS) (e.g., Illumina sequencing platforms) to 16S rDNA gene amplicon sequencing provides the high resolution required for studying the composition of bacterial and archaeal communities of feedstock substrates (Lim et al. 2017), anaerobic digesters (Vanwonterghem et al. 2014; Bozan et al. 2017), anaerobic digestion residues (Oszust et al. 2015), and soil after residue application as a source of exogenous organic matter (Su et al. 2017). 
Among the various types of feedstock biomass available for the production of biogas, corn silage is currently the most favoured, particularly in Central and Western Europe (Oleszek et al. 2016). However, a sufficient yield of corn, as well as cellulose-based substrates obtained from energy plants biomass, e.g., miscanthus, reed canary grass, or Virginia mallow, may be obtained only from fertile soils, which should rather be used for food production, not for energy crops (Giovannetti and Ticci 2016). Moreover, pretreated cellulosic biomass realize high yields that are crucial to commercial success in biological conversion (Wyman et al. 2005). Although many pretreatment methods are known, e.g., ammonia explosion, aqueous ammonia recycle, controlled $\mathrm{pH}$, dilute acid, flow through, lime, or biological approaches (Wyman et al. 2005; Maroušek and Kwan 2013), additional steps, especially enzymes hydrolytic application, may increase the total costs of biogas production (Zheng et al. 2009).

As an alternative for corn or energy plants, organic waste-based type fermentation substrates were previously studied (Oszust et al. 2017). The cited authors indicated that lower biogas yields are obtained from waste, compared with corn silage. However, substrates mixed for co-fermentation produce satisfactory results (Gómez et al. 2016; Böjti et al. 2017). In some countries (Germany, Italy) it is permitted to add energy-rich substrates (up to 20\%) to make reactors more efficient (Insam et al. 2015).

In choosing substrates for biogas production, the quantity of these substrates available in the local area matters (Montusiewicz and Lebiocka 2011). The constitution of these substrates should also be taken into consideration, especially the biodegradable compound content and microbiological composition. The methane yields from cow manure, chicken manure, and a straw mixture ratio have been reported (Li et al. 2017). Furthermore, food expellers and sludge can be used for biogas production by anaerobic fermentation (Oszust et al. 2017).

Fruit industry wastes, dairy sewage sludge, and grass, especially those acquired from fallow lands, are readily available and suitable for biodegradation, material recovery, and energy production. Using such substrates can reduce the cost of the process, because there are no transportation expenses. What is more, such substrates are permitted by legislation (Frąc and Ziemiński 2012). Waste from fruit processing residues consists mainly of woody stalks and leaves. These are produced in large quantities and constitute a source of nutrients (cell wall polysaccharides, such as pectin, cellulose, and hemicellulose) (Bouallagui et al. 2005). Similarly, sewage sludge, a byproduct of the dairy industry, is a valuable substrate for methane production because it is rich in fat and protein (Frąc et al. 2014).

The agrochemical value of the residues biomass from a biofermenter was evaluated previously (Kolár et al. 2010). As a fertilizer in general terms it was reported to have higher ion exchange and buffering capacity than the material before anaerobic fermentation (Kolár et al. 2008). Advantages of applying biochar from the fermentation residue in crop production were explained previously by Maroušek (2014). Thus, biogas residues may be converted to a variety of value-added byproducts that can be applied to the soil (Chanakya et al. 1999). Thus, the utilization of biogas residue as exogenous organic matter for field applications is a form of soil conditioning to enhance crop yield. The microbial biomass and metabolic activities of soil are comprehensively stimulated after the application of digestate residues; this phenomenon is attributed to the supplementation of the levels of carbon and nutrients in the soil (Frąc 2012). Therefore, the soil microbial response after residue application is currently being evaluated (Van Nguyen et al. 2017). Biogas residues are also valuable products because they contain microbial components, which provide the key factor to ensure the success of anaerobic digestion. To the best of our knowledge, the methanogen composition of residues has not been analysed thoroughly to date. The most recent study of Zhao et al. (2017) highlights the role of microbes in choosing acclimated anaerobic sludge (biogas residues) as microbial and nutritional regulators to improve the biomethanation of fruit wastes. The hypothesis of our work was that microbial community composition of dairy sewage sludge, corn silage, grass straw, fruit waste 
biomass differs among each other. Moreover, their resulting digestate residues are varied, and elucidating microbial community composition may suggest the most relevant ways to manage or utilize these types of biomass.

The purpose of the study was to link microbial community composition and chemical properties of dairy sewage sludge, corn silage, grass straw, fruit waste biomass, and their resulting digestate residues for their potential use in biogas production or soil enrichment. Therefore, we 1) evaluated the physicochemical properties of feedstock substrates and digestate residues, and 2) determined their core microbial community composition of biogas substrates and digestate residues. It is worth mentioning that the metagenomics of the microbial community in fruit waste and dairy sewage sludge has not been reported before. This research intends to elucidate the role of the biomass microbial community for biogas yield effectiveness, and determine the role of methanogens, which occur in digestate residues, following biogas production. Thus, the biogas yield kinetic study of substrates was linked to the physiochemical parameters and microbial community composition. What is more, both opportunities and threats related to incorporating biomass into the soil are highlighted.

\section{EXPERIMENTAL}

\section{Biomass Characteristic}

Eight different organic biomasses were evaluated: fruit waste $(\mathrm{FW})$, dairy sewage sludge (DSS), grass straw (GS), corn silage (CS), fruit waste digestate residues (FWR), dairy sewage sludge digestate residues (DSSR), grass straw digestate residues (GSR), and corn silage digestate residues (CSR).

FW - waste from soft fruit processing residues consists mainly of spoiled raspberries, strawberries, and currants peel expeller and pulp flakes after squeezing the juice, as well as woody stalks and leaves;

DSS - waste taken from the dairy company, where it was formed in a mechanicalbiological treatment plant as excess sludge after purification of wastewaters from technological lines;

GS - an air-dried mix of the most common grass species found in Poland, namely: Phragmites australis, Poa pratensis, Festuca arundinacea, Festuca rubra, Elymus (Agropyron) repens, Dactylis glomerata, Arrhenatherum elatius, Lolium perrene, Calamagrostis epigejos;

$\mathrm{CS}$ - prepared from corn forage ensiled in silos and covered by foil, exposed to air prior to anaerobic digestion

FWR, DSSR, GSR, CSR were generated in anaerobic digestion of FW, DSS, GS, CS, respectively as described below. Each of the biomass samples was transported in a portable refrigerator into the laboratory and afterwards frozen immediately for further analyses.

\section{Anaerobic Digestion}

The details of the anaerobic digestion experiment are shown in Table 1. Based on the preliminary results, the initial load for the fermenter was selected. The weighed portion of the 2 to $4 \mathrm{~mm}$ feedstock substrate along with the inoculum was placed in a sealed fermentation vessel with a working $500 \mathrm{~mL}$ volume. The fermenters (three replications for each substrate) were placed in a $37^{\circ} \mathrm{C}$ water bath. The biogas was transferred to a cylindrical, calibrated gas manifold filled with acidified water. The accumulated gas displaces water from the collector to an overflow tank. The level of gas in the collector was recorded every $24 \mathrm{~h}$. An analysis of biogas composition was performed periodically. Fermentation was carried out until there were no significant increases in biogas volume. For this study an anaerobic sediment (obtained from and standardized by the laboratory of Biogaz Zeneris Sp. z o. o., Poznań, Poland) that was starved and nonadapted was used as the inoculum. The term "nonadapted" indicates that the 
sediment was not, prior to the experiment, supplied with the substrate for which biogas potential was investigated. Biogas composition was determined by (1) biogas analyser GA 2000 Plus (Geotech, Rzeszów, Poland), (2) GFM 410 (GAS DATA Ltd., Coventry, Great Britain); analyses included: $\mathrm{CH}_{4}, \mathrm{CO}_{2}, \mathrm{O}_{2}, \mathrm{NH}_{3}, \mathrm{H}_{2} \mathrm{~S}$ and $\mathrm{H}_{2}$ ), and (3) VARIAN MicroGC - 4900 gas chromatograph (Palo Alto, USA); analyses included: $\mathrm{CH}_{4}, \mathrm{CO}_{2}, \mathrm{O}_{2}, \mathrm{~N}_{2}, \mathrm{H}_{2} \mathrm{~S}$, and $\mathrm{H}_{2}$ ).

Table 1. Anaerobic Digestion Parameters

\begin{tabular}{|c|c|c|c|c|}
\hline Parameter & FW & DSS & GS & CS \\
\hline Total fermentation time $(\mathrm{d})$ & \multicolumn{2}{|c|}{41} & \multicolumn{2}{|c|}{36} \\
\hline Time in which $90 \%$ of biogas was generated (d) & 9 & 12 & 12 & 8 \\
\hline Working capacity of fermenters $\left(\mathrm{cm}^{3}\right)$ & \multicolumn{4}{|c|}{500} \\
\hline Initial loading of the fermenter (kg o.d.m. $/ \mathrm{m}^{3}$ ) & \multicolumn{4}{|c|}{4.95} \\
\hline Initial loading of the fermenter $\left(\mathrm{kg} \mathrm{O}_{2} / \mathrm{m}^{3}\right)$ & 6.36 & 11.57 & 11.41 & 6.16 \\
\hline Fermented substrate mass $(\mathrm{g})$ & 32.47 & 17.38 & 4.71 & 7.2 \\
\hline Fermentation temperature $\left({ }^{\circ} \mathrm{C}\right)$ & \multicolumn{4}{|c|}{37} \\
\hline Substrate particle diameter $(\mathrm{mm})$ & \multicolumn{4}{|c|}{$2-4$} \\
\hline
\end{tabular}

\section{Physicochemical properties of biomass}

Dry matter (d.m.) was evaluated using the gravimetric method, organic dry matter (o.d.m.) was also evaluated using the gravimetric method, $\mathrm{pH}$ was measured using the electrometric method, and ammonium nitrogen (AN) was determined with Spectroquant cuvette tests (MERCK). Total nitrogen (TN) was determined using the Kjeldahl method (\% d.m.), whereas total carbon (TC) was determined using solid sample mineralization in a furnace and the detection of combustion products in the detector of the central unit of the TOC apparatus, according to (Szarlip et al. 2014). Chemical oxygen demand (COD) was evaluated using the dichromate method; volatile fatty acid (VFA) content was determined using the Spectroquant tube test assay in supernatant after centrifugation (MERCK). The total ion content $(\mathrm{Cr}, \mathrm{Ni}, \mathrm{Cu}, \mathrm{Zn}, \mathrm{Cd}, \mathrm{Pb}, \mathrm{Mg}, \mathrm{K}, \mathrm{Ca}, \mathrm{Hg}$, and $\mathrm{P}$ ) of the substrates was evaluated using the inductively coupled plasma with mass spectrometry (ICP-MS) method after microwave digestion (Gałązka and Gembal 2015).

\section{Metagenomic Analysis by NGS}

DNA isolation

The DNA from different types of biomass was extracted using a FAST DNA Spin Kit for Feces (MPBiomedicals, Santa Ana, CA, USA) according to the protocol, as described previously by Gryta et al. (2017). The amount of DNA was determined by a NanoDrop ${ }^{\circledR} 2000$ spectrophotometer (Thermo Scientific ${ }^{\mathrm{TM}}$, Waltham, MA, USA).

\section{S rDNA gene amplification and amplicon sequencing}

The MiSeq 2000 platform (Illumina Inc., San Diego, CA, USA) was applied to sequence the DNA of microorganisms. Polymerase chain reaction (PCR) was performed with NebNext High-Fidelity 2x PCR Master Mix (New England BioLabs, Ipswich, MA, USA) according to the manufacturer's protocol and the following primers: 515F (5'-AAT GAT ACG GCG ACC ACC GAG ATC TAC ACT ATG GTA ATT GTG TGC CAG CMG CCG CGG TAA-3') and 806R (5'-CAA GCA GAA GAC GGC ATA CGA GAT XXX XXX XXX XXX AGT CAG TCA GCC GGA CTA CHV GGG TWTCTA AT-3') for the v4 region of 16S rDNA (Caporaso et al. 2012). The conditions for the $16 \mathrm{~S}$ rDNA genes were as follows: $94{ }^{\circ} \mathrm{C}$ for $3 \mathrm{~min} ; 35$ cycles of $94{ }^{\circ} \mathrm{C}$ for $45 \mathrm{~s}, 50{ }^{\circ} \mathrm{C}$ for $60 \mathrm{~s}$, and $72{ }^{\circ} \mathrm{C}$ for $90 \mathrm{~s}$; and a final extension at $72{ }^{\circ} \mathrm{C}$ for $10 \mathrm{~min}$. The libraries were indexed in TrueSeq (Illumina, San Diego, CA, USA). Sequencing was performed in PE reads 2 x 250 bp with an Illumina v2 MiSeq reagent kit. 


\section{Calculations}

\section{Processing of the sequencing data}

A bioinformatics assay was carried out based on the reference sequence database Greengenes_13_05 (DeSantis et al. 2006) and was performed using an algorithm from Qiime software (Caporaso et al. 2010). The analysis included the following steps: demultiplexing of samples and adaptor cutting, quality analysis, taxonomic composition, and diversity analysis. Sequences which were over $97 \%$ identical were grouped into one operational taxonomic unit (OTU) using a distance-based OTU program. The application of MiSeq Reporter v2.3 allowed for classifications at a species level. The taxonomy database for the metagenomics workflow was the Illumina version of the Greengenes database (DeSantis et al. 2006).

\section{Statistical analysis}

All statistical analyses were performed on operational taxonomic units (OTUs) data > $1 \%$ of occurrence at least in one sample. The dendrogram was based on scaled axis bond distances (Ward's method, within Euclidean distance), with marked boundaries of Sneath's criteria. Cluster analyses were performed using Statistica software (version 10.0). Dissimilarity displays were made using Similarity Percentages (SIMPER) software. Principal component analysis (PCA) was performed using the PAST 3.14 program (Hammer et al. 2008). Thus, multivariate analysis with ordination was applied to generate a biplot. The Krona visualization tool allowed for the exploration of relative abundances, and confidences within the hierarchies of metagenomics classifications were used (Ondov et al. 2011). Similarity percentages - family contributions were calculated using the PRIMER 7 program (Clarke and Gorley 2006).

\section{RESULTS}

\section{Physicochemical Properties of Biomass}

Daily gas production increased gradually as the microbial community adapted to the reactor environment. The highest cumulative biogas and methane yield was noted from anaerobic digestion of silages. In CS it was $533 \mathrm{dm}^{3} / \mathrm{kg} \mathrm{d.m.} \mathrm{and} 356 \mathrm{dm}^{3} / \mathrm{kg} \mathrm{d.m}$., accordingly. However the highest methane content in biogas was achieved after DSS digestion $(75.7 \%)$. The highest daily biogas production as depicted by constant biogas yield was obtained on the fourteenth day of the anaerobic digestion process (Fig. 1).

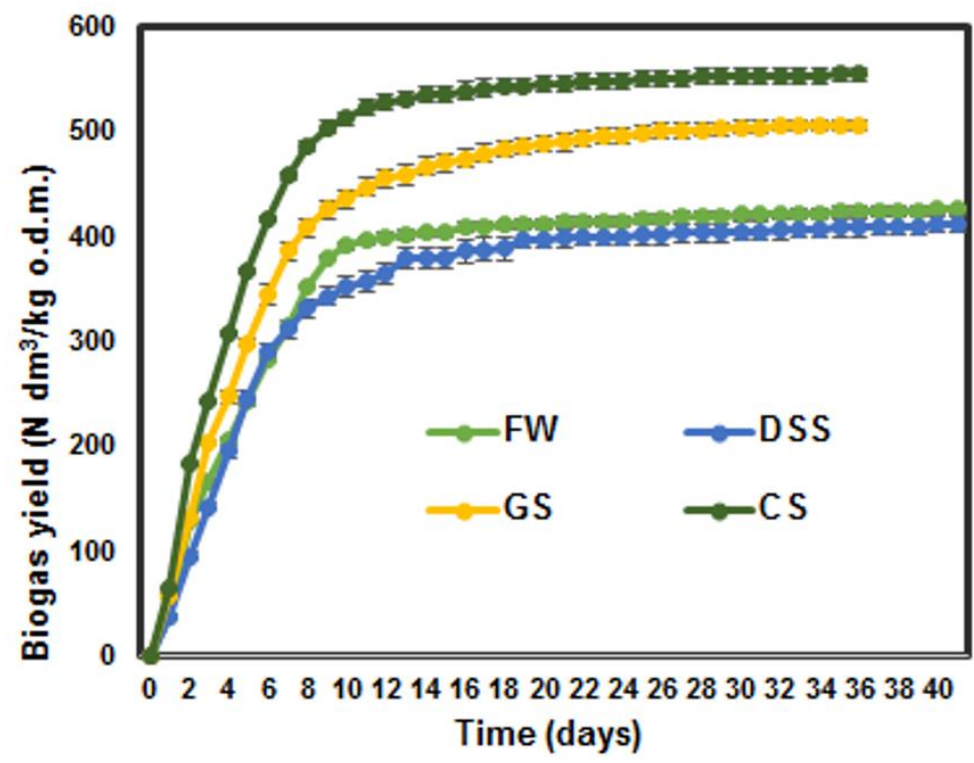

Fig. 1. Efficiency of anaerobic digestion. Explanations: please see Table 1. Vertical bars indicate standard deviations, $\mathrm{n}=3$ 
Table 2. Physicochemical Properties of Biomass

\begin{tabular}{|c|c|c|c|c|c|c|c|c|}
\hline Parameter & $\mathrm{FW}$ & DSS & GS & $\mathrm{CS}$ & FWR & DSSR & GSR & CSR \\
\hline d.m. (\%) & 8.1 & 16.4 & 60.6 & 34.6 & 0.82 & 1.21 & 0.97 & 0.87 \\
\hline o.d.m. (\% d.m.) & 94.1 & 86.9 & 86.7 & 96.4 & $-?$ & - & - & - \\
\hline Ash (\% d.m.) & 5.9 & 13.1 & 13.3 & 3.6 & - & - & - & - \\
\hline $\mathrm{pH}$ & 3.09 & 5.91 & 5.59 & 3.89 & 8.31 & 8.32 & 8.30 & 8.23 \\
\hline $\mathrm{COD}\left(\mathrm{g} \mathrm{O}_{2} \mathrm{~g}^{-1}\right.$ d.m.) & 1.21 & 2.03 & 2 & 1.2 & - & - & - & - \\
\hline TN (\% d.m.) & 2.36 & 7.9 & 1.93 & 1.39 & 0.02 & 0.02 & 0.02 & 0.02 \\
\hline $\mathrm{C} / \mathrm{N}$ & 21.8 & 5.1 & 16.3 & 30.1 & 10.8 & 10.2 & 11.8 & 14.2 \\
\hline 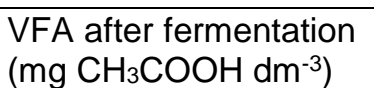 & - & - & - & - & 259 & 398 & 384 & 285 \\
\hline $\begin{array}{l}\text { AN after fermentation } \\
\left(\mathrm{mg} \mathrm{NH}_{4} \mathrm{dm}^{-3}\right)\end{array}$ & - & - & - & - & 1181 & 1561 & 1534 & 1239 \\
\hline $\mathrm{Cr}(\mathrm{ppm})$ & $3.82 \pm 0.07$ & $8.28 \pm 0.44$ & $22.89 \pm 2.23$ & $3.46 \pm 0.09$ & $24.27 \pm 8.82$ & $18.7 \pm 0.83$ & $24.45 \pm 2.17$ & $19.23 \pm 1.17$ \\
\hline $\mathrm{Ni}(\mathrm{ppm})$ & $2.98 \pm 0.09$ & $3.59 \pm 0.12$ & $8.05 \pm 0.93$ & $0.72 \pm 0.02$ & $14.85 \pm 1.01$ & $12.57 \pm 0.58$ & $14.62 \pm 1.15$ & $13.53 \pm 0.58$ \\
\hline Cu (ppm) & $9.05 \pm 0.85$ & $12.62 \pm 0.46$ & $11.34 \pm 4.34$ & $3.42 \pm 0.10$ & $247 \pm 7.15$ & $268 \pm 24$ & $254 \pm 9.47$ & $302 \pm 29$ \\
\hline $\mathrm{Zn}(\mathrm{ppm})$ & $44.70 \pm 1.21$ & $89.42 \pm 2.99$ & $62.67 \pm 27.69$ & $25.40 \pm 1.18$ & $650 \pm 15.44$ & $703 \pm 39$ & $657 \pm 31$ & $769 \pm 81$ \\
\hline $\mathrm{Mg}(\mathrm{ppm})$ & $1386 \pm 7.31$ & $2804 \pm 43$ & $2835 \pm 352$ & $1153 \pm 47$ & $13059 \pm 918$ & $14580 \pm 2093$ & $14575 \pm 1110$ & $14820 \pm 2174$ \\
\hline $\mathrm{K}(\mathrm{ppm})$ & $10747 \pm 312$ & $8041 \pm 458$ & $7349 \pm 1095$ & $8683 \pm 120$ & $126271 \pm 11400$ & $90869 \pm 4476$ & $102137 \pm 8077$ & $124478 \pm 10038$ \\
\hline $\mathrm{Ca}(\mathrm{ppm})$ & $4137 \pm 79$ & $29272 \pm 940$ & $14804 \pm 4890$ & $1903 \pm 89$ & $33633 \pm 186$ & $58360 \pm 13336$ & $39887 \pm 2976$ & $39452 \pm 4481$ \\
\hline $\mathrm{Hg}(\mathrm{ppm})$ & $0.01 \pm 0.00$ & $0.03 \pm 0.00$ & $0.02 \pm 0.00$ & $0.01 \pm 0.00$ & $0.32 \pm 0.21$ & $0.66 \pm 0.12$ & $0.31 \pm 0.26$ & $0.57 \pm 0.1$ \\
\hline $\mathrm{P}(\mathrm{ppm})$ & $2366 \pm 38$ & $18317 \pm 254$ & $2591 \pm 1015$ & $1880 \pm 45$ & $76669 \pm 899$ & $83292 \pm 3762$ & $89454 \pm 4905$ & $87811 \pm 2731$ \\
\hline
\end{tabular}


The following chemical properties of the feedstock substrates (fruit waste (FW), dairy sewage sludge (DSS), grass silage (GS), and corn silage (CS)) were evaluated: dry matter (d.m.), organic dry matter, ash, $\mathrm{pH}$, ammonium nitrogen, total nitrogen, total organic carbon, chemical oxygen demand, volatile fatty acids, the content of elements, and biogas composition (Tables 2 and 3).

Table 3. Biogas Yield and Composition

\begin{tabular}{|c|c|c|c|c|c|}
\hline \multicolumn{2}{|r|}{ Yield } & FW & DSS & GS & CS \\
\hline \multirow{2}{*}{ Biogas } & $N\left(\mathrm{dm}^{3} \mathrm{~kg}^{-1}\right.$ d.m. $)$ & 400.09 & 356.50 & 438.29 & 533.43 \\
\hline & $\mathrm{N}\left(\mathrm{dm}^{3} \mathrm{~kg}^{-1}\right.$ o.d.m. $)$ & 425.17 & 410.25 & 505.52 & 533.34 \\
\hline \multirow{2}{*}{ Methane } & $\mathrm{N}\left(\mathrm{dm}^{3} \mathrm{CH}_{4} \mathrm{~kg}^{-1}\right.$ d.m.) & 277.09 & 269.89 & 284.90 & 343.71 \\
\hline & $\mathrm{N} \mathrm{dm}{ }^{3}\left(\mathrm{CH}_{4} \mathrm{~kg}^{-1}\right.$ o.d.m. $)$ & 294.46 & 310.57 & 328.60 & 356.55 \\
\hline \multirow{7}{*}{$\begin{array}{l}\text { Biogas composition } \\
(\% \mathrm{v} / \mathrm{v})\end{array}$} & $\mathrm{CH}_{4}(\%)$ & 69.25 & 75.70 & 65.01 & 64.44 \\
\hline & $\mathrm{CO}_{2}(\%)$ & 25.24 & 16.47 & 27.55 & 28.13 \\
\hline & $\mathrm{O}_{2}(\%)$ & 1.20 & 1.04 & 1.33 & 1.02 \\
\hline & $\mathrm{H}_{2} \mathrm{~S}(\mathrm{ppm})$ & 38.66 & 78.75 & 56.60 & 48.58 \\
\hline & $\mathrm{H}_{2}(\mathrm{ppm})$ & 0.00 & 0.00 & 0.00 & 0.00 \\
\hline & $\mathrm{NH}_{3}(\mathrm{ppm})$ & 117.01 & 218.75 & 174.37 & 129.92 \\
\hline & Other gases ${ }^{*}(\%)$ & 4.31 & 6.80 & 6.11 & 6.41 \\
\hline
\end{tabular}

Dry matter content ranged from $8.1 \%$ in FW to $60.6 \%$ in GS. Organic dry matter content in DSS and GS was relatively constant and reached $86 \%$ d.m. In CS and FW, organic dry matter was found to be from $94 \%$ to $96 \%$ d.m. Ash content in the tested samples was rather low (from $3 \%$ to $13 \%$ ). The highest amount of total nitrogen was measured in DSS (7.9\% d.m.), and the lowest amount of total nitrogen was measured in CS and GS (1.39\% d.m. and $1.93 \%$ d.m., respectively). Substrates showed different $\mathrm{C} / \mathrm{N}$ ratios. This ratio reached 21.8, 5.1, 16.3, and 30.1 in FW, DSS, GS, and CS, respectively. The VFA after fermentation ranged from $259 \mathrm{mg}$ $\mathrm{CH}_{3} \mathrm{COOH} \mathrm{dm}{ }^{-3}$ in $\mathrm{FW}, 285 \mathrm{mg}$ in CS, $384 \mathrm{mg}$ in GS, and $398 \mathrm{mg}$ in DSS. Ammonium nitrogen after fermentation was lower in FW and CS $\left(1181 \mathrm{mg} \mathrm{NH}_{4}{ }^{+} \mathrm{dm}^{-3}\right.$ and $\left.1239 \mathrm{mg} \mathrm{NH}_{4}{ }^{+} \mathrm{dm}^{-3}\right)$ than in DSS and GS (1561 mg NH $4{ }_{4}^{+} \mathrm{dm}^{-3}$ and $1534 \mathrm{mg} \mathrm{NH}_{4}{ }^{+} \mathrm{dm}^{-3}$, respectively). The amounts of such heavy metals as $\mathrm{Cr}, \mathrm{Ni}, \mathrm{Cu}, \mathrm{Cd}, \mathrm{Pb}$, and $\mathrm{Hg}$ ranged from less than $1 \mathrm{ppm}$ to $23 \mathrm{ppm}$. Slightly higher amounts of Zn were noted, they ranged from 25 ppm, 44 ppm, 63 ppm, and 89 ppm in CS, FW, GS, and DSS, respectively. Phosphorus content was rather constant in the tested samples. Substrates differed significantly as far as K and Ca content were concerned. Ca amounts of 4137 ppm, 14804 ppm, 1909 ppm, and 29272 ppm were noted in FW, GS, CS, and DSS, respectively. As far as residues ions content was noted to be higher than in substrates. Macroelements like $\mathrm{K}$ and $\mathrm{P}$ contents increased in residues, however $\mathrm{N}$ decreased. For example from $7.9 \%$ d.m. in DSS and $2.36 \%$ d.m. in FW to $0.02 \%$ d.m. in corresponding residues, with disparate d.m. content for the tested biomass.

\section{Biomass Metagenomic Analysis by NGS}

The obtained sequences, among feedstocks and resulting digestate residues were classified into 11 phyla (Euryarchaeota, Actinobacteria, Bacteroidetes, Chloroflexi, Cyanobacteria, Fibrobacteres, Firmicutes, Planctomycetes, Proteobacteria, Spirochaetes, and Synergistetes), one unidentified phylum, 16 classes, within 26 orders and 48 families (with 13 separate but not identified) across the entire data set. Although the $16 \mathrm{~S}$ rRNA sequencing currently represents the most important study target in bacterial ecology, this is biased by the 
presence of variable copy numbers in bacterial genomes and sequence variation within closely related taxa or within a genome (Větrovský and Baldrian 2013).

The results of cluster analysis shown in Fig. 2 indicated evident differences among the samples when the family level of taxonomic classifications was taken into consideration. A dendrogram with clustering samples taken at the family level according to stringent Sneath's criteria revealed residues that form groups, which indicates that their microbial communities compositions were similar. Each sample of the substrate represented a separate group when strict criteria are applied. The FW and DSS met the 66\% similarity criterion, and they represented one group that indicates that microbial composition might be similar.

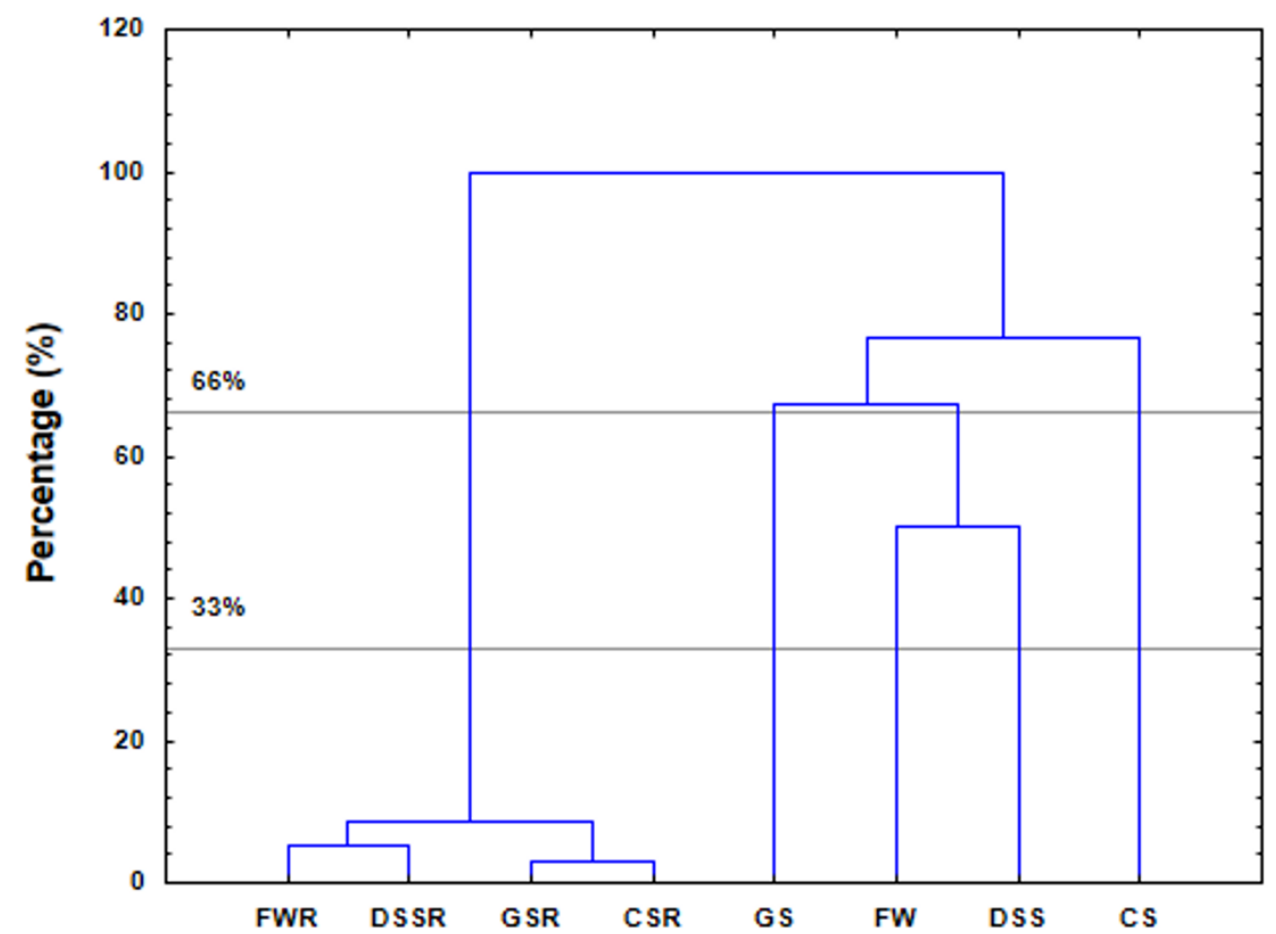

Fig. 2. Dendrogram with clustering samples on family level according to the stringent Sneath's criterion (33\%) and less restrictive criterion (66\%). Explanations: "f" family non-identified, classification according to order, fruit waste (FW), dairy sewage sludge (DSS), grass straw (GS), corn silage (CS), digestate fruit waste residues (FWR), dairy sewage sludge residues (DSSR), grass straw residues (GSR), and corn silage residues (CSR)

The average dissimilarity displayed for each pairwise combination (Simper approach) of feedstock and residues groups as presented in Table 4 and the indices show how the sample communities differ and what is the particular contribution to this dissimilarity for each particular family. Among residues, the average microbial dissimilarity was low, indicating relatively high resemblance between communities, that ranged between $7.79 \%$ dissimilarity for CSR and GSR to $20.09 \%$ for DSSR and GSR; whereas in substrates the range went from 85.56\% for DSS and FW to $98.14 \%$ for CS and GS. When comparing CS and GS, the largest influence on the disparity between those two samples was Acetobacteraceae (30.45\%), GS and DSS - Bacillaceae (24.50\%), FW and CS - Acetobacteraceae (32.50\%), DSS and CS Acetobacteraceae (32.36\%), FW and GS - Streptophyta (27.73\%), DSS and FW - Streptophyta (29.26\%), DSSR and GSR - Marinilabiaceae (15.30\%), CSR and DSSR - Marinilabiaceae (15.06\%), FWR and DSSR - Tissierellaceae (12.48\%), CSR and FWR - Marinilabiaceae (15.12\%), GSR and FWR - Marinilabiaceae (18.30\%), CSR and GSR - Propionibacteriaceae (14.38\%). This supports the findings of cluster analysis (Fig. 2) with respect to the residues grouped together. 


\section{bioresources.com}

Table 4. Dissimilarity Displayed for Each Pair-Wise Combination of Feedstock and Residues Groups

\begin{tabular}{|c|c|c|c|c|c|}
\hline \multicolumn{2}{|c|}{ CS and GS } & \multicolumn{2}{|c|}{ GS and DSS } & \multicolumn{2}{|c|}{ FW and CS } \\
\hline \multicolumn{2}{|c|}{ Average dissimilarity $=98.14 \%$} & \multicolumn{2}{|c|}{ Average dissimilarity $=97.06 \%$} & \multicolumn{2}{|c|}{ Average dissimilarity $=92.59 \%$} \\
\hline Acetobacteraceae & 30.45 & Bacillaceae & 24.50 & Acetobacteraceae & 32.50 \\
\hline Bacillaceae & 24.62 & Planococcaceae & 22.79 & Streptophyta_f & 27.51 \\
\hline \multirow[t]{3}{*}{ Planococcaceae } & 22.95 & Xanthomonadaceae & 13.01 & Lactobacillaceae & 16.78 \\
\hline & & Enterococcaceae & 9.12 & & \\
\hline & & Nocardiopsaceae & 5.54 & & \\
\hline \multicolumn{2}{|c|}{ DSS and CS } & \multicolumn{2}{|c|}{ FW and GS } & \multicolumn{2}{|c|}{ DSS and FW } \\
\hline \multicolumn{2}{|c|}{ Average dissimilarity $=92.28 \%$} & \multicolumn{2}{|c|}{ Average dissimilarity $=90.23 \%$} & \multicolumn{2}{|c|}{ Average dissimilarity $=85.56 \%$} \\
\hline Acetobacteraceae & 32.36 & Streptophyta_f & 27.73 & Streptophyta_f & 29.26 \\
\hline Lactobacillaceae & 16.14 & Bacillaceae & 23.93 & Xanthomonadaceae & 14.85 \\
\hline Xanthomonadaceae & 13.91 & Planococcaceae & 23.44 & Enterococcaceae & 10.50 \\
\hline \multirow[t]{3}{*}{ Enterococcaceae } & 9.77 & & & Rickettsiales_f & 8.23 \\
\hline & & & & Nocardiopsaceae & 4.80 \\
\hline & & & & Rhizobiales_f & 3.77 \\
\hline
\end{tabular}

Explanations: "ff" family non-identified, classification according to order, fruit waste (FW), dairy sewage sludge (DSS), grass straw (GS), corn silage $(\mathrm{CS})$, digestate fruit waste residues (FWR), dairy sewage sludge residues (DSSR), grass straw residues (GSR), and corn silage residues (CSR) 
Table 4 cont. Dissimilarity Displayed for Each Pair-Wise Combination of Feedstock and Residues Groups

\begin{tabular}{|l|c|l|c|l|c|}
\hline \multicolumn{2}{|c|}{ DSSR and GSR } & \multicolumn{2}{c|}{ CSR and DSSR } & \multicolumn{2}{c|}{ FWR and DSSR } \\
\hline Average dissimilarity $=20.09 \%$ & Average dissimilarity $=18.79 \%$ & \multicolumn{2}{l|}{ Average dissimilarity =17.63\% } \\
\hline Marinilabiaceae & 15.30 & Marinilabiaceae & 15.06 & Tissierellaceae & 12.48 \\
\hline Tissierellaceae & 10.95 & Nocardiopsaceae & 8.70 & Bacteria_f & 10.22 \\
\hline Nocardiopsaceae & 8.33 & Tissierellaceae & 8.26 & Nocardiopsaceae & 9.70 \\
\hline Fibrobacteres_f & 6.21 & Clostridia_f & 5.88 & Clostridia_f & 6.87 \\
\hline Clostridia_f & 5.57 & Spirochaetaceae & 4.97 & Bacteroidales_f & 6.76 \\
\hline Methanosaetaceae & 4.33 & Methanospirillaceae & 4.84 & Propionibacteriaceae & 6.02 \\
\hline Clostridiaceae & 4.18 & Propionibacteriaceae & 4.08 & Clostridiaceae & 5.27 \\
\hline Methylocystaceae & 3.82 & Methylocystaceae & 4.04 & Methylocystaceae & 4.37 \\
\hline Methanospirillaceae & 3.51 & Methanosaetaceae & 4.01 & Rhizobiales_f & 3.33 \\
\hline Spirochaetaceae & 3.07 & Fibrobacteres_f & 3.52 & Methanobacteriaceae & 2.69 \\
\hline Peptostreptococcaceae & 3.04 & Rhizobiales_f & 3.19 & Rhodobacteraceae & 2.62 \\
\hline Rhizobiales_f & 3.01 & Bacteroidales_f & 3.06 & & \\
\hline \multicolumn{1}{|c|}{ CSR and FWR and FWR } & & & \multicolumn{1}{c|}{ CSR and GSR } \\
\hline Average dissimilarity $=16.60 \%$ & & Average dissimilarity $=15.07 \%$ & Average dissimilarity $=7.79 \%$ \\
\hline Marinilabiaceae & 15.12 & Marinilabiaceae & 18.30 & Propionibacteriaceae & 14.38 \\
\hline Bacteria_f & 12.95 & Bacteria_f & 10.02 & Bacteria_f & 8.42 \\
\hline Propionibacteriaceae & 11.28 & Bacteroidales_f & 8.52 & Tissierellaceae & 8.23 \\
\hline Methanosaetaceae & 6.18 & Methanosaetaceae & 7.85 & Fibrobacteres_f & 7.56 \\
\hline Spirochaetaceae & 6.17 & Methanospirillaceae & 7.63 & Clostridiaceae & 7.19 \\
\hline Methanospirillaceae & 5.87 & Propionibacteriaceae & 5.07 & Bacteroidales & 7.04 \\
\hline Fibrobacteres_f & 4.08 & Spirochaetaceae & 5.03 & Bacillaceae & 5.18 \\
\hline Clostridiaceae & 3.92 & Porphyromonadaceae & 4.63 & Spirochaetaceae & 4.27 \\
\hline Tissierellaceae & 3.84 & & 3.71 & Lachnospiraceae & 3.44 \\
\hline Porphyromonadaceae & 3.83 & & & & 2.85 \\
\hline Explanations: please see Table 4 & & & & \\
\hline
\end{tabular}




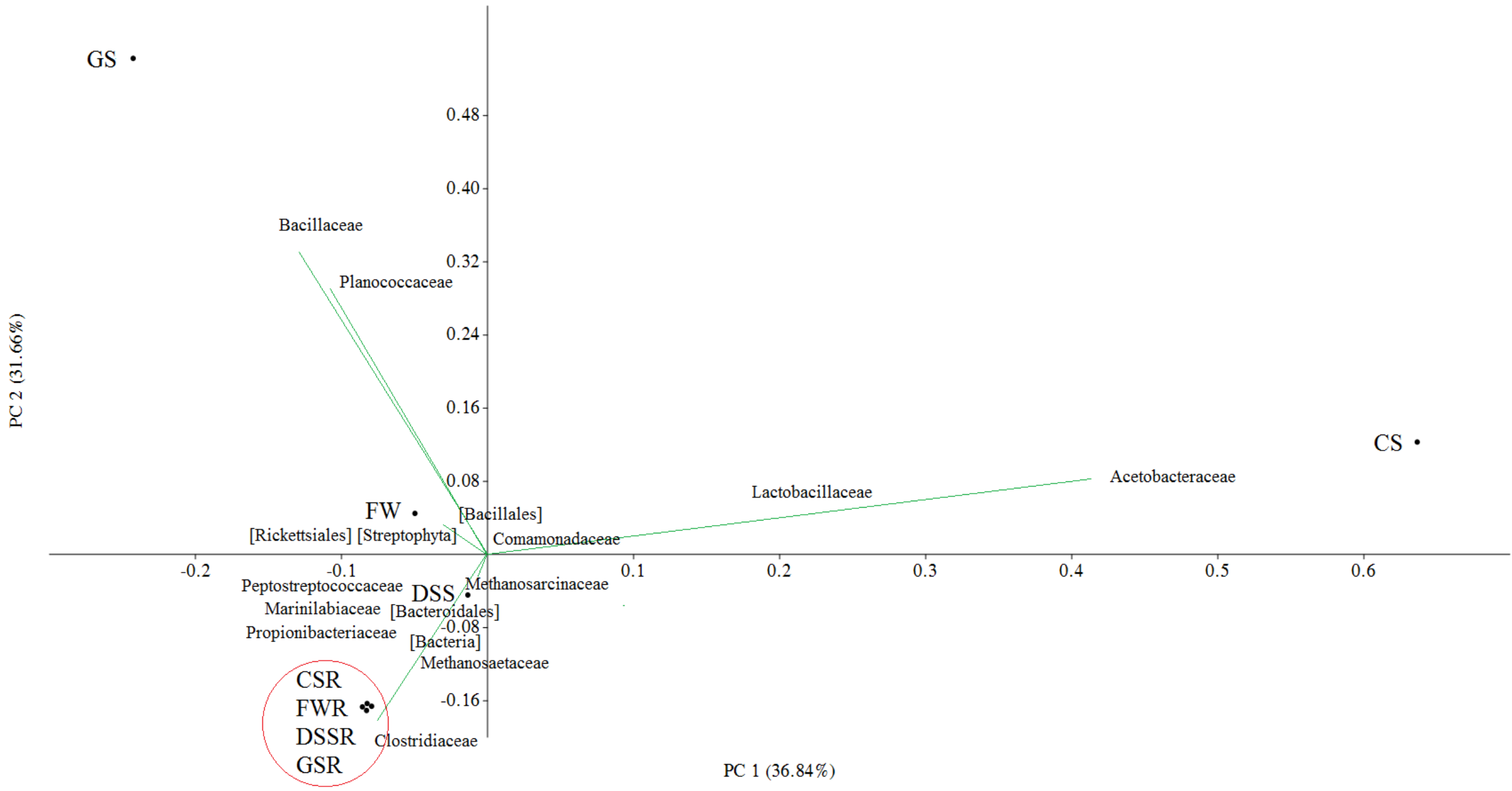

Fig. 3. The environment-vector view of the microbial composition biplot on family level (a). Explanations: please see Table 4 
$\mathrm{b}$

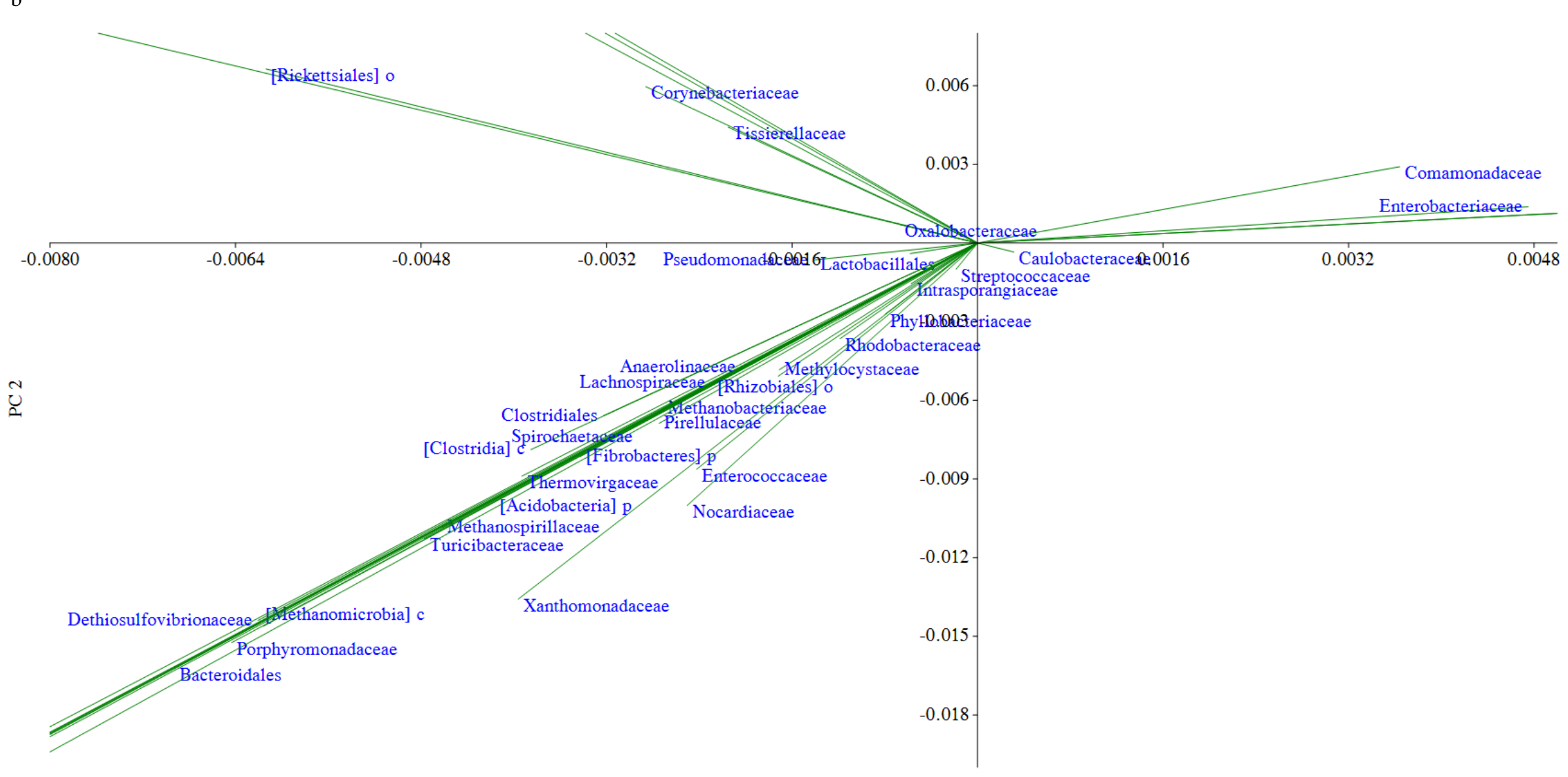

PC 1

Fig. 3 cont. The environment-vector view of the microbial composition narrowed down biplot on family level (b). Explanations: please see Table 4. 
Even closely similar microbial composition (dissimilarity <20\%, as measured by the percentage of its abundance contribution) may be considered. Nevertheless, this approach provides an insight into the differences in pairwise combinations of samples. The general overview on sample grouping with respect to microbial relative abundance and its taxonomic classification are shown in the biplot exploratory graph (Fig. 3) of principal component analysis (PCA). The corresponding results to cluster analyses and the Simper approach are to be found in PCA. PC1 and PC2 explained $31.66 \%$ and $36.84 \%$ of the variance. Biplot vectors clearly indicate that families mainly occurred in tested substrates and residues. CS was mostly inhabited by Acetobacteraceae (63.9\% of the individuals among the whole community) and Lactobacillaceae (31.8\% among all of the revealed families in total); GS by Bacillaceae (49.2\%) and Planococcaceae $(45.2 \%)$, DSS by Xanthomonadaceae $(23.7 \%)$, Enterococcaceae $(16.1 \%)$, Nocardioidaceae $(9.5 \%)$, unidentified family of the Rhizobiales order $(5.5 \%)$ and others from Proteobacteria $(<4.5 \%)$ (Caulobacteraceae, Methylocystaceae, Phyllobacteriaceae, Rhodobacteraceae) and Firmicutes (<3.2\%) (Lactobacillaceae, Streptococcaceae); FW was primarily inhabited by an unidentified family from the Streptophyta order $(51.3 \%)$ and an unidentified family from Rickettsiales (12.4\%). Residues are differentiated as far as microbial composition is concerned compared to the substrates. The dissimilarity resulted from a higher content of Clostridiales, especially Clostridiaceae $(22.5 \%-23.9 \%)$ than in the substrates $(<1.5 \%)$. After anaerobic digestion in biogas residues Euryarcheota (Methanosaetaceae primarily from $12.5 \%$ to $14.7 \%$ of all the families) and Bacteroidetes (Propionibacteriaceae, Marinilabiaceae, Porphyromonadaceae, and two unidentified families) were noted, whereas in substrates, their amount was rather low $<0.2 \%$.

Figure $4(\mathrm{a}-\mathrm{d})$ particularly represents the archaeal community composition of biogas residues (CSR, GSR, DSSR, FWR, respectively). Archaea communities comprised $21 \%$ of the whole microbial community tested using the $16 \mathrm{~S}$ rDNA marker in CSR and GSR, whereas DSSR and FWR were 20\% and 22\%, respectively. In CSR only Euryarcheota (100\%) occurred. This is the methanogens group, and $91 \%$ of it consisted of Methanobacteriales (Methanosaetaceae 60\%, Methanosarcinaceae 14\%, Methanospirillaceae 11\%, Methanobacteriaceae 5\%) and 9\% belonged to an unidentified order. The GSR community composition was found to be similar to CSR (1\% dissparity) (Table 4). In FWR, Methanobacteriales (93\% of Methanobacteria) consisted of the following families: Methanosaetaceae (73\%), Methanosarcinaceae (17\%), Methanobacteriaceae (6\%), Methanospirillaceae (3\%), Methanocorpusculaceae (1\%). Among Methanobacteriales of DSSR (90\% Methanobacteria) as much as $77 \%$ was Methanosaetaceae, $15 \%$ was Methanosarcinaceae, 4\% Methanospirillaceae, 2\% Methanospirillaceae and 2\% Methanocorpusculaceae.

\section{DISCUSSION}

The production of methane via the anaerobic digestion of organic substrates within the inoculum including methanogenic Archaea is accomplished by the intricate relationship of microbial communities of feedstock substrates and inoculum components. According to Perrotta et al. (2017), inoculum-specific outcomes in the experiment, where different inocula and the same substrate are subjected to anaerobic digestion, suggests the influence of such factors as species-species interaction. We assumed that apparently the relatively analogical situation occurs if an attempt includes the use of the same inoculum for diverse substrates. Thus, occurring interaction depends on both chemical properties of substrates and their inherent microbial community composition. Consequently, biogas yield strictly depends on its chemical composition and on the susceptibility of its organic compounds to decomposition under anaerobic conditions (Vanwonterghem et al. 2014; De Vrieze and Verstraete 2016; Fitamo et al. 2017a). 
a

$\mathrm{b}$
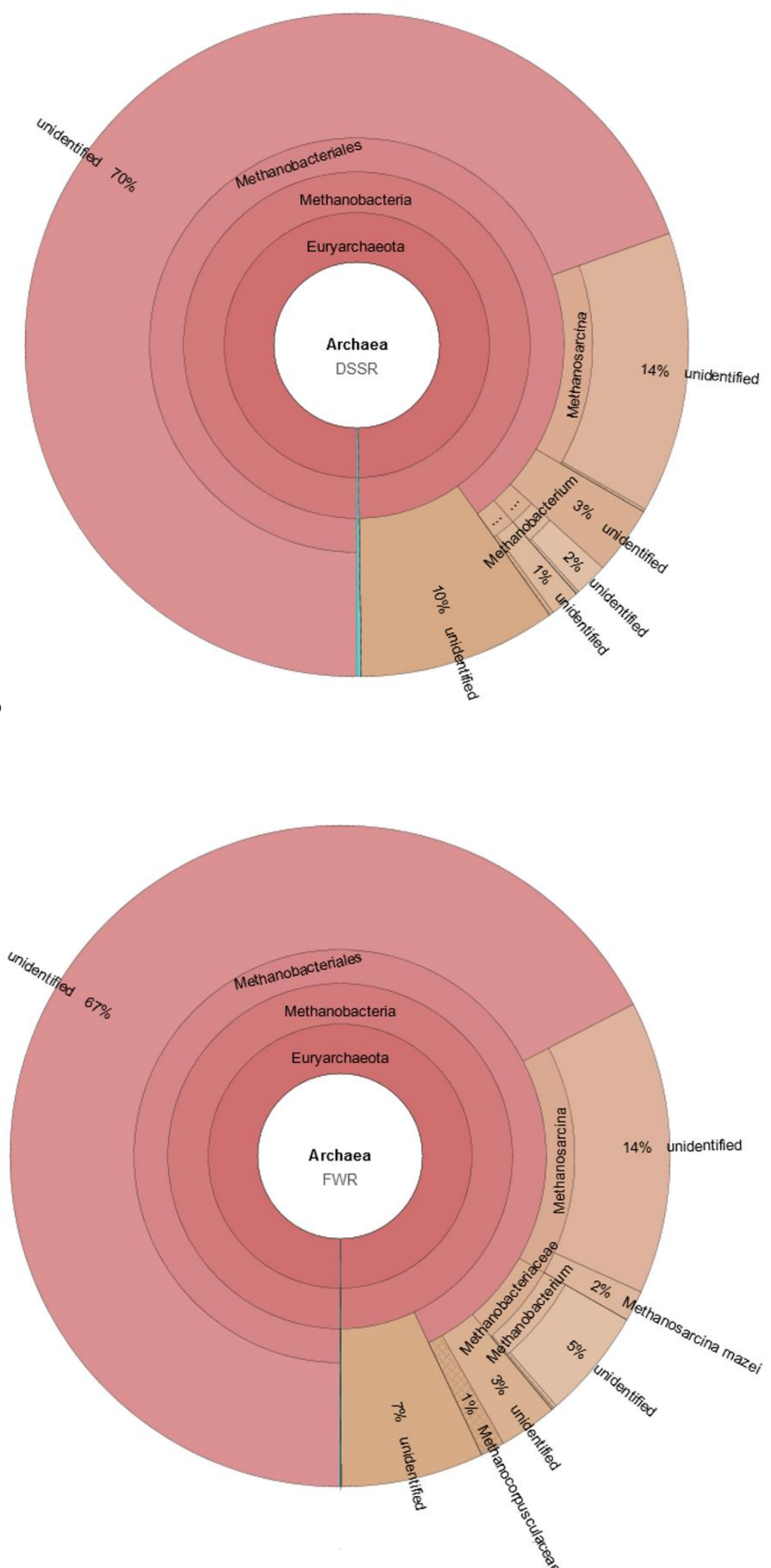

Fig. 4. Methanogen's community composition of biogas residues (a) dairy sewage sludge (DSSR), (b) fruit waste (FWR) 
c
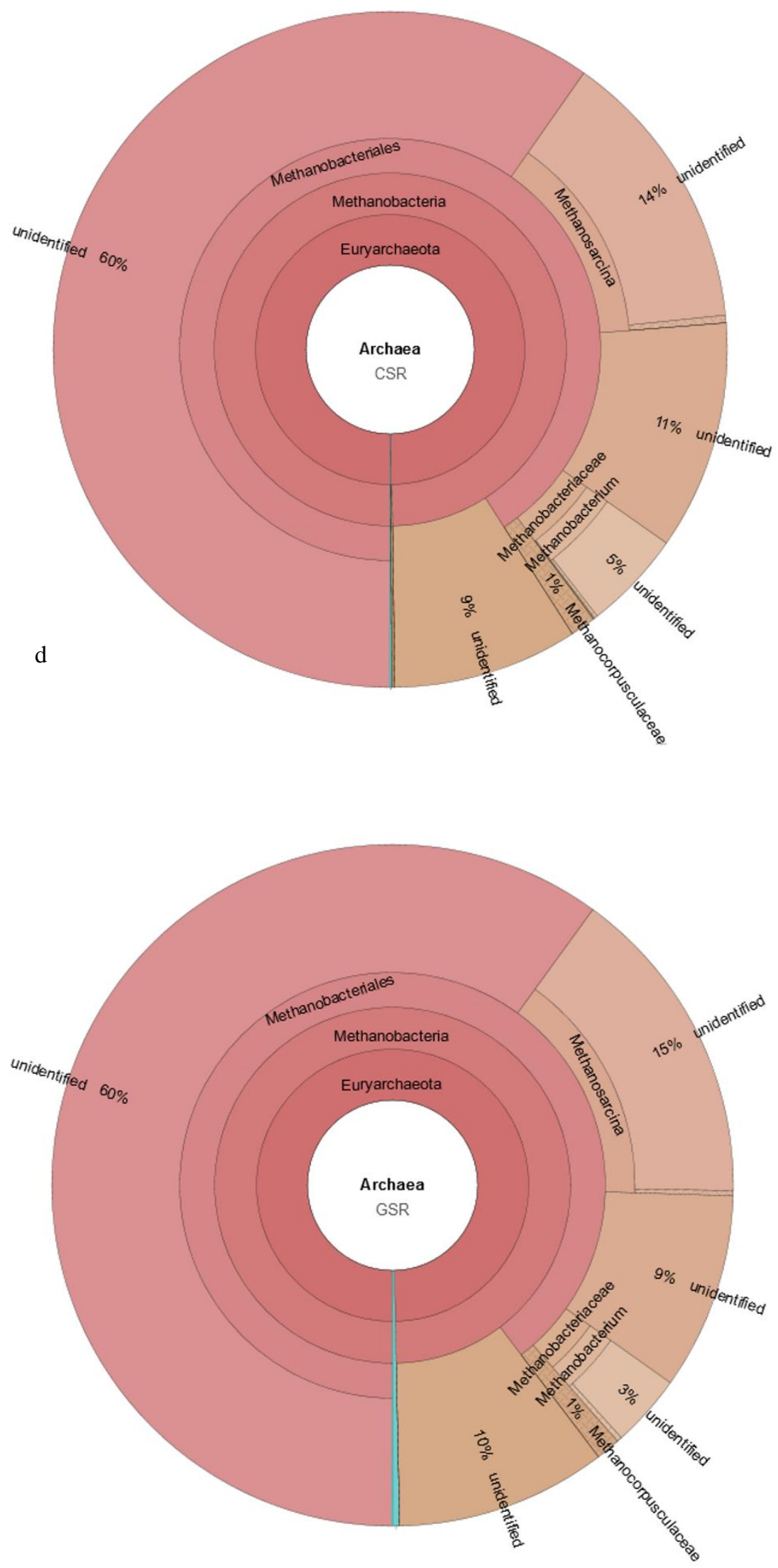

Fig. 4 cont. Methanogen's community composition of biogas residues (c) corn silage (CSR), (d) grass straw (GSR) 
In general, hydrolysis is the limiting step of bioconversion, especially from lignocellulosic materials (Veeken and Hamelers 1999). However, the anaerobic degradation of cellulose-poor wastes (dairy sewage sludge) is more limited by methanogenesis rather than by the hydrolysis (Bouallagui et al. 2005). This very first step of anaerobic digestion is important since large organic molecules are not readily degradable. Several microbes secrete different enzymes, which cut the complex macromolecules into simpler forms. Microorganisms that are active during the hydrolysis of polysaccharides include various bacterial groups such as Clostridium, Bacteriodetes, and Acetivibrio (Heeg et al. 2014), that have cellulosomes - large, stable, multi-enzyme complexes specialized in the adhesion and degradation of cellulose, which is located in the cell wall (Bayer 2017). The complex structure of cellulose affects its microbial degradation capability, which limits decomposition and acid production, as we observed in fruit waste. The pre-treated lignocellulosic load to the fermenter (using the physical, chemical or/and biological method) is recognized to result in an increase in anaerobic digestion process efficiency (Oszust et al. 2017).

The ensiling process is a pretreatment strategy that does not change the degree of lignification; however, there is a microbiologically catalysed release of plain sugars, crude protein, and crude fat, which are subsequently rapidly metabolized into volatile fatty acids by microorganisms in the reactor. Previously, representatives of the Lactobacillaceae family were found in corn (Basso et al. 2012) silages, since they form rich habitats where carbohydrate-containing substrates are available (Felis and Pot 2014). However, corn silage is susceptible to aerobic deterioration, primarily in warm weather, because microorganisms that utilize the lactic acid, produced by lactic acid bacteria, as a source of energy. Probably the conditions of ensiling process in the present experiments were deficient with respect to oxygenation. Thus, we observed overgrowth of Acetobacteraceae on Lactobacillaceae. This results in lower-quality silages for animals feeding (Basso et al. 2012), but not for biogas production. This is because acetic acid bacteria have a great ability to oxidize sugars, sugar alcohols, and ethanol into their corresponding acids. Acetic, as well as propionic and butyric acid are important volatile fatty acids produced during anaerobic digestion (Cibis et al. 2016).

Bacillaceae and Planococcaceae (belonging to order Bacillales) were the most prevalent group in grass straw. These families are common plant-associated bacteria, and they have a more epiphytic character with mostly plant growth and health promoting roles. They are generally aerobic heat resistant endospore formers (Shivaji et al. 2014). Bacillaceae were also found in grass straw residues which means, that were able to survive anaerobic digestion and may be the additional value while soil application, as a load of beneficial microorganisms. With rather no hydrolytic capabilities their role in very beginning steps and simultaneously crucial for anaerobic digestion remains rather negligible.

A very different profile of the microbial community of non-cellulose substrate such as dairy sewage sludge was observed. It was noted that Xanthomonadaceae, Enterococcaceae, and Nocardioidaceae were the dominant families in DSS feedstocks (Fig. 3 , Table 4). Though the Xanthomonadaceae family constitutes the main contribution to the dairy sewage sludge microbial community, its function in dairy sewage sludge remains unclear. This family includes the two plant-pathogenic genera (Xanthomonas and Xylella), which have a virulence mechanism that may also pose a threat to humans and animals (Mhedbi-Hajri et al. 2011). However, Xanthomonadales endospores are not produced (Naushad et al. 2015) and vegetative forms do not survive anaerobic digestion. For this 
reason, we did not observed Xanthomonadaceae in residues. Therefore, residue discharge into soil is safe in this context and dependably complies with recycling and disposal requirements. The activity of Xanthomonadaceae may be linked to the synthesis of phenol (Pascual et al. 2017). Phenols that are produced or introduced into the anaerobic digestion process may cause problems due to their inhibition of acetate-utilizing methanogens. On the other hand, there are previously described methanogenic consortia, which degrade phenol to acetate (Levén et al. 2012). Consequently, CSR and GSR were found to be inhabited by phenol-degrading Syntrophorhabdaceae population microbial component $(<0.01 \%$ relative abundance).

The saprophytic Enterococci colonize milk and multiply in these materials during processing because of their ability to survive adverse environmental conditions such as extreme $\mathrm{pH}$, temperatures, and salinity. The presence of Enterococcaceae in foods, contrary to what has been commonly stated, has been shown to be unrelated with direct fecal contamination (Giraffa 2003). The authors highlight the significance of saprophytic Enterococci for its application in dairy products technology. Their substantial functionality is based on acidifying, proteolytic, peptidolytic, lipolytic and esterase activities and citrate and pyruvate metabolism. To the best of our knowledge the significance of this group for anaerobic digestion has been poorly described but far-reaching. The breakdown of lactose and citrate in the first stages of anaerobic digestion of dairy sewage sludge gives rise to a series of volatile compounds, such as acetaldehyde, ethanol, diacetyl, acetone, and acetoin, which further contribute to biogas production since they serve as substrates for the functioning of other microbial groups leading to acetogenesis. On the other hand, dairy sewage sludge were utilized as biofertilizers under crops (Frąc et al. 2012). Authors evaluated microbial activity of soil after dairy sewage sludge application, but not community composition (Oszust et al. 2017). Nevertheless, the hydrolytic role of saprophytic Enterococci introduced into the soil with this biomass may be subdued by the development of fast-growing fungi, that have better ability to degrade organic matter.

Streptophyta and Rickettsiales were also found to be very prevalent groups in fruit waste. Streptophyta has been noticed in decomposed organic material previously (Hospodsky et al. 2012). Both family members may play an important role in the first step of the hydrolytic decomposition of organic waste components. Rickettsia were detected in a number of vertebrate hosts, including humans. Thus, Rickettsia ecology research is quite medically oriented (Yu and Walker 2006). The reason of occurring Rickettsiales in fruit waste remains unclear, nevertheless this findings indicate waste application into the soil as exogenous organic matter without proper treatment (e.g. anaerobic digestion) may pose presumed microbiological threat. This aspect was previously highlighted by Oszust et al. (2018). Adding organic waste directly into the soil is either useful due to the organic matter and nutrients introduced; however, their microbiological quality should be monitored before agricultural application.

Wide-ranging observations from previous studies have established how reactor setup, operational conditions, and substrate composition influence the anaerobic digestion process and the community composition (Gaida et al. 2017; Westerholm et al. 2017). Vochozka and Maroušková (2017) concluded that biogas is produced based on organic substance content in substrates, but not all of the substrates are equally subjected to methane fermentation. These findings are consistent with the present results of biogas yield and substrate composition. The order of biogas production obtained here, ranged from high to low was as follows: corn silage, grass straw, fruit waste, and dairy sewage sludge (Table 3). A gradual increase in gas production within subsequent days of anaerobic digestion 
(observed in Fig. 1), regardless of the substrate, was attributed to a drop in the rates of acid hydrolysis and acidification processes conducted by bacteria during anaerobic transformation. The enhancement in the decomposition rate by methanogens diminished gas production, as explained by Li et al. (2017). In the context of substrate composition, the present results are consistent with the findings of Lalak et al. (2015). Carbohydrates of corn silage showed the fastest conversion rates of gas yields, resulting mainly from the decomposition of starch, in much lower amounts of lignocellulose. Conversely, lipids and proteins occurring in diary sewage sludge generated the lowest biogas yield, due to their low biodegradability, however, the biogas generated had the highest methane content (Table 3), that is to say, the biogas had the most desirable quality. In compliance with the statement of Zhao et al. (2017), the proteins and lipids in dairy sewage sludge could not be thoroughly degraded and transformed to methane or biomass.

The ratio of carbon and nitrogen is really crucial for the absolute majority of microorganisms. According to previous study (Wang et al. 2014) the first insight into estimating the quantity of organic compounds, potentially capable of converting into biogas, depends on the mass (or volume) unit of the substrate. The $\mathrm{C} / \mathrm{N}$ ratio, indicating that the optimal $\mathrm{C} / \mathrm{N}$ ratios in methane fermentation is regarded to reach 15 to 30 . Among the compared substrates, only dairy sewage sludge showed a $\mathrm{C} / \mathrm{N}$ ratio below the optimum mentioned above, which primarily indicates the high amount of nitrogen bound in proteins. Consequently, this forms the basis that links the low anaerobic digestion yield from dairy sewage sludge with inhibition by ammonium released from its proteins. However, according to recent research of Maroušek et al. (2017) the actual C and N content may differ if substrate pretreatment applied prior to anaerobic digestion or diverse methods practiced for the evaluation.

Ions are crucial also for anaerobic digestion. These parameters are consequently beneficial for microbial growth and viability and thus helpful for biogas production in anaerobic digestion (Goswami et al. 2016). The authors have thoroughly summarized the crucial role of important ion channels in the growth of methanogenic microorganisms. The growth of methanogens is dependent on a few ions, among others: $\mathrm{Na}, \mathrm{Ni}, \mathrm{Co}, \mathrm{Fe}, \mathrm{Zn}, \mathrm{Mg}$, $\mathrm{Ca}$ and $\mathrm{K}$ cations and molybdate or tungstate and phosphate anions. Except for $\mathrm{Na}$, which is required for coupling methanogenesis with ADP phosphorylation, all of the other ions are required for the synthesis of enzymes, prosthetic groups, and coenzymes. In the work of Zhang et al. (2008), the limiting amounts of ions have been indicated as $\mathrm{Fe}$ at a concentration of $5 \mathrm{mg} \mathrm{l}^{-1}, \mathrm{Zn}$ at $1 \mathrm{mg} \mathrm{l}^{-1}, \mathrm{Cu}$ at $0.1 \mathrm{mg} \mathrm{l}^{-1}$, $\mathrm{Ni}$ at $1.2 \mathrm{mg} \mathrm{l}^{-1}$, and $\mathrm{Co}$ at $4.8 \mathrm{mg}$ $1^{-1}$, respectively. The relatively high concentrations of ions obtained in our work (Table 3 ) might have a limiting effect on the functionality of methanogens. Mixing substrates for codigestion were previously shown to decrease the susceptibility of methanogenesis on the limiting effect of ions, which occurred in substrates and/or an increase in the biogas yield from proposed substrates (Oszust et al. 2017). The relatively higher amounts of C, P, K, and $\mathrm{Ca}$ found in digestate residues, than in feedstock substrates suggests that nutrients may be delivered with digestate residues. However dry matter content should be taken under consideration when calculating doses, and EU limit values for heavy metals should be observed when the material is used for agricultural soils, as summarized by Frąc et al. (2012).

From another side, using the residues to serve as an inoculum as proposed in this study is expected to be profitable since these residues contain a robust and wide range of methanogens. Methanosaetaceae were the most abundant organisms in all of the residues tested, which means that mainly aceticlastic conversion to methane was observed, as was 
described by Karakashev et al. (2006). What is more, the high ratio of Methanosaetaceae to Methanosarcinaceae indicated quite a low acetate threshold, growth rate, and yield susceptibility, as previously noted by Gryta et al. (2017). On the other hand, it has been observed that Clostridium spp. forms a syntrophic association with hydrogenotrophic methanogens - Methanobacteriales. This shows the occurrence of a second mechanism of methanogenesis that encompasses a two-step reaction in which acetate is first oxidized to $\mathrm{H}_{2}$ and $\mathrm{CO}_{2}$ and, with these products, subsequently converted to methane. The possibility of producing methane via both mechanisms, because of increasing the biodiversity of the methanogens of the inoculum is very desirable. However, there are some important environmental factors influencing the rate of their activity. These factors have been widely described and include temperature, organic acid concentrations, and ammonia concentration in substrates (Cavinato et al. 2017; Fitamo et al. 2017b; Munk et al. 2017), these factors should all be taken into consideration.

In summary, it is worth to mention that the results of the present study can be helpful in economic and financial calculations for companies by application or utilization of different types of biomass, taking under consideration their microbial community structure. Knowledge on microorganisms composition in tested biomass and digested residues indicates their possible uses, as fertilizers, inoculum, biopreparation, which is important from the economical point of view. Bearing in mind the microbiological composition of different kind of biomass and their economic values, farmers and agro-food companies should also consider various biotechnological solutions for biomass transformations and uses.

\section{CONCLUSIONS}

1. The microbial community composition of dairy sewage sludge, corn silage, grass straw, fruit waste biomass, and their resulting digestate residues provided indications regarding their potential utilization.

2. Corn silage, which is regarded unsuitable for animal feed due to deterioration as a result of long term air exposition, serves as an efficient feedstock substrate for anaerobic digestion with Acetobacteraceae overgrowth on Lactobacillaceae (with biogas yield rating $533 \mathrm{dm}^{3} \mathrm{~kg}^{-1}$ o.d.m.).

3. Grass straw, representing not-pretreated cellulose-based feedstock substrate, is relatively productive in anaerobic digestion $\left(506 \mathrm{dm}^{3} \mathrm{~kg}^{-1}\right.$ o.d.m.), however with limited portrayal of dominating microbes (Bacillaceae and Planococcaceae) in hydrolytic decomposition prior to fermentation. The positive role in plant biocontrol of Bacillaceae and Planococcaceae, which were found in grass straw residues, and reasonable biogas yield obtained from this substrate support a recommendation to use grass straw for biogas production and its residues to enrich the soil.

4. Due to potential threat of introducing pathogens into the soil within organic waste such as fruit waste (Rickettsiales) or dairy sewage sludge (Xanthomonas and Xylella genera of Xanthomonadaceae family) field application, this biomass should be microbiologically analyzed and if necessary sanitized prior to soil application in e.g. in anaerobic digestion. Simultaneously, low biogas yields (410 and $425 \mathrm{dm}^{3} \mathrm{~kg}^{-1}$ o.d.m., respectively) from fruit waste and dairy sewage sludge substrates impose necessity to transform them in anaerobic digestion with more energetic co-substrates. 
5. Tested residues may deliver a robust and wide range of methanogens as inoculum for further anaerobic digestion process and also are appropriate for agricultural application.

\section{ACKNOWLEDGMENTS}

Scientific work was funded from the budget for science by The National Centre for Research and Development in Poland. LIDER 048/L-2/10. Programme 2011-2014.

\section{REFERENCES CITED}

Bayer, E. A. (2017). "Cellulosomes and designer cellulosomes, why toy with Nature?," Env. Microbiol. Rep. 9(1), 14-15. DOI: 10.1111/1758-2229.12489

Böjti, T., Kovács, K. L., Kakuk, B., Wirth, R., Rákhely, G., and Bagi, Z. (2017). "Pretreatment of poultry manure for efficient biogas production as monosubstrate or co-fermentation with maize silage and corn stover," Anaerobe 46, 138-145. DOI: 10.1016/j.anaerobe.2017.03.017

Bouallagui, H., Touhami, Y., Cheikh, R. B., and Hamdi, M. (2005). "Bioreactor performance in anaerobic digestion of fruit and vegetable wastes," Process Biochem. 40(3-4), 989-995. DOI: 10.1016/j.procbio.2004.03.007

Basso, F. C., Bernardes, T. F., Roth A. P., Lodo B. N., Berchielli, T. T., and Reis, R. A. (2012). "Fermentation and aerobic stability of corn silage inoculated with Lactobacillus buchneri," Revista Brasileira de Zootecnia 41(1), 1789-1794. DOI: 10.1590/S1516-35982012000700032

Bozan, M., Akyol, Ç., Ince, O., Aydin, S., and Ince, B. (2017). "Application of nextgeneration sequencing methods for microbial monitoring of anaerobic digestion of lignocellulosic biomass," Appl. Microbiol. Biot. 101(18), 6849-6864. DOI: $10.1007 / \mathrm{s} 00253-017-8438-7$

Caporaso, J. G., Kuczynski, J., Stombaugh, J., Bittinger, K., Bushman, F. D., Costello, E. K., Fierer, N., Peña, A. G., Goodrich, J. K., Gordon, J. I., Huttley, G. A., Kelley, S. T., Knights, D., Koenig, J. E., Ley, R. E., Lozupone, C. A., McDonald, D., Muegge, B. D., Pirrung, M., Reeder, J., Sevinsky, J. R., Turnbaugh, P. J., Walters, W. A., Widmann, J., Yatsunenko, T., Zaneveld, J., and Knight, R. (2010). "QIIME allows analysis of high-throughput community sequencing data," Nat. Methods 7(5), 335-6. DOI: $10.1038 /$ nmeth.f.303

Caporaso, J. G., Lauber, C. L., Walters, W. A., Berg-Lyons, D., Huntley, J., Fierer, N., Owens, S. M., Betley, J., Fraser, L., and Bauer, M. (2012). "Ultra-high-throughput microbial community analysis on the Illumina Hiseq and Miseq Platforms," Isme Journal 6, 1621. DOI: 10.1038/ismej.2012.8

Cavinato, C., Da Ros, C., Pavan, P., and Bolzonella, D. (2017). "Influence of temperature and hydraulic retention on the production of volatile fatty acids during anaerobic fermentation of cow manure and maize silage," Bioresource Technol. 223, 59-64. DOI: 10.1016/j.biortech.2016.10.041

Chanakya, H., Srikumar, K., Anand, V., Modak, J., and Jagadish, K. (1999). "Fermentation properties of agro-residues, leaf biomass and urban market garbage in a solid phase biogas fermenter," Biomass Bioeng. 16(6), 417-429. DOI: 10.1016/S0961-9534(99)00015-X 
Cibis, K. G., Gneipel, A., and König, H. (2016). "Isolation of acetic, propionic and butyric acid-forming bacteria from biogas plants," J. Biotechnol. 220, 51-63. DOI: 10.1016/j.jbiotec.2016.01.008

Clarke, K. R., and Gorley, R. N. (2006). "PRIMER v6: User Manual - Tutorial, PRIMER-E", second ed. Plymouth, UK.

De Vrieze, J., and Verstraete, W. (2016). "Perspectives for microbial community composition in anaerobic digestion, from abundance and activity to connectivity," Environ. Microbiol. 18, 2797-2809. DOI: 10.1111/1462-2920.13437

Desantis, T., Hugenholtz, P., Keller, K., Brodie, E., Larsen, N., Piceno, Y., Phan, R., Andersen, G.L., and Nast, A. (2006). "NAST: A multiple sequence alignment server for comparative analysis of 16S RNA genes," Nucleic Acids Res. 34, 394-399. DOI: $10.1111 / 1462-2920.13437$

Felis, G. E., and Pot, B. (2014). "The family Lactobacillaceae," in Lactic Acid Bacteria: Biodiversity and Taxonomy, W. H. Holzapfel and B. J. B. Wood (eds.), John Wiley \& Sons, Ltd, Chichester, UK, pp. 245-247. DOI: 10.1002/9781118655252.part4

Fitamo, T., Treu, L., Boldrin, A., Sartori, C., Angelidaki, I., and Scheutz, C. (2017a). "Microbial population dynamics in urban organic waste anaerobic co-digestion with mixed sludge during a change in feedstock composition and different hydraulic retention times," Water Res. 118, 261-271. DOI: 10.1016/j.watres.2017.04.012

Fitamo, T., Triolo, J. M., Boldrin, A., and Scheutz, C. (2017b). "Rapid biochemical methane potential prediction of urban organic waste with near-infrared reflectance spectroscopy," Water Res. 119, 242-251. DOI: 10.1016/j.watres.2017.04.051

Frąc, M. (2012). "Ocena mikologiczna osadu z oczyszczalni ścieków mleczarskich oraz jego wpływ na różnorodność funkcjonalną mikroorganizmów glebowych

[Mycological assessment of sediment from sewage treatment plant and its impact on functional diversity of soil microorganisms]," Acta Agrophysica Monographiae 1, 1142.

Frac, M., Oszust, K., and Lipiec, J. (2012). "Community level physiological profiles (CLPP), characterization and microbial activity of soil amended with dairy sewage sludge," Sensors 12, 3253-3268. DOI: 10.3390/s120303253

Frąc, M., Oszust, K., Lipiec, J., Jezierska-Tys, S., and Nwaichi, E. O. (2014). "Soil microbial functional and fungal diversity as influenced by municipal sewage sludge accumulation," Int. J. Environ. Res. Pub. He. 11(9), 8891-8908.

Frąc, M., and Ziemiński K. (2012). "Methane fermentation process for utilization of organic waste," Int. Agrophys. 26(3), 317-330. DOI:10.2478/v10247-012-0045-3

Gaida, D., Wolf, C., and Bongards, M. (2017). "Feed control of anaerobic digestion processes for renewable energy production: A review," Renewable and Sustainable Energy Reviews 68(2), 869-875. DOI: 10.1016/j.rser.2016.06.096

Gałązka, R., and Gembal, A. (2015). "Determination of different forms of trace elements and macro elements," in: Laboratory Manual, A. Bieganowski, S. Malý, M. Frąc, I. H. Tuf, M. Váňa, M Brzezińska, G. Siebielec, L. Lipiec, and B. Šarapatka (eds.) Central Institute for Supervising and Testing in Agriculture. Brno, Czech Republic, pp. 91-96.

Giovannetti, G., and Ticci, E. (2016). "Determinants of biofuel-oriented land acquisitions in sub-saharan Africa," Renewable and Sustainable Energy Reviews 54, 678-687. DOI: $10.1016 /$ j.rser.2015.10.008

Giraffa, G. (2003). "Functionality of enterococci in dairy products," Int. J. Food Microbiol. 88(2-3), 215-222. 10.1016/S0168-1605(03)00183-1 
Goswami, R., Chattopadhyay, P., Shome, A., Banerjee, S. N., Chakraborty, A. K., Mathew, A. K., and Chaudhury, S. (2016). "An overview of physico-chemical mechanisms of biogas production by microbial communities, a step towards sustainable waste management," 3 Biotechnol. 6, 72. DOI: 10.1007/s13205-0160395-9

Gómez, J. S., Lohmann, H., and Krassowski, J. (2016). "Determination of volatile organic compounds from biowaste and co-fermentation biogas plants by singlesorbent adsorption," Chemosphere 153, 48-57. DOI:

10.1016/j.chemosphere.2016.02.128

Gryta, A., Oszust, K., Brzezińska, M., Ziemiński, K., Bilińska-Wielgus, N., and Frąc, M., (2017). "Methanogenic community composition in an organic waste mixture in an anaerobic bioreactor," Int. Agrophys. 31(3), 327-338. DOI: 10.1515/intag-2016-0057.

Hammer, Ø., Harper, D., and Ryan, P. (2008). "Past-palaeontological statistics, Ver. 1.89," Paleontological Museum, University of Oslo, Noruega.

Heeg, K., Pohl, M., Sontag, M., Mumme, J., Klocke, M., and Nettmann, E. (2014). "Microbial communities involved in biogas production from wheat straw as the sole substrate within a two-phase solid-state anaerobic digestion," Syst. Appl. Microbiol. 37(8), 590-600. DOI: 10.1016/j.syapm.2014.10.002

Hospodsky, D., Qian, J., Nazaroff, W. W., Yamamoto, N., Bibby, K., Rismani-Yazdi, H., and Peccia, J. (2012). "Human occupancy as a source of indoor airborne bacteria.," PLOS One 7, e34867. DOI: 10.1371/journal.pone.0034867

Insam, H., Gómez-Brandón, M., and Ascher, J. (2015). "Manure-based biogas fermentation residues - Friend or foe of soil fertility?" Soil Biol. Biochem. 84, 1-14. DOI: $10.1016 /$ j.soilbio.2015.02.006

Karakashev, D., Batstone, D.J., Trably, E., and Angelidaki, I. (2006). "Acetate oxidation is the dominant methanogenic pathway from acetate in the absence of methanosaetaceae," Appl. Envir. Microb. 72(7), 5138-5141. DOI: 10.1128/AEM.00489-06

Kolár̆, L., Kužel, S., Peterka, J., and Borová-Batt, J. (2010). "Agrochemical value of the liquid phase of wastes from fermenters during biogas production," Plant Soil Environ. 56(1), 23-27. DOI: 10.17221/180/2009-PSE

Kolář, L., Kužel, S., Peterka, J., Štindl, P., and Plát, V. (2008)."Agrochemical value of organic matter of fermenter wastes in biogas production," Plant Soil Environ. 54(8), 321-328. DOI: 10.17221/412-PSE

Lalak, J., Kasprzycka, A., Paprota E. M., Tys J., and Murat A. (2015). "Development of optimum substrate compositions in the methane fermentation process," Int. Agrophys. 29(3), 313-321

Levén, L., Nyberg, K., and Schnürer, A. (2012). "Conversion of phenols during anaerobic digestion of organic solid waste - A review of important microorganisms and impact of temperature," J. Environ. Manage. 95, 99-103. DOI: 10.1016/j.jenvman.2010.10.021

Li, X., Liu, Y. H., Zhang, X., Ge, C. M., Piao, R. Z., Wang, W. D., Cui, Z. J., and Zhao, H. Y. (2017). "Evaluation of biogas production performance and dynamics of the microbial community in different straws," J. Microbiol. Biotechnol. 27(3), 524-534. DOI: $0.4014 /$ jmb.1608.08062

Lim, J. W., Ge, T., and Tong, Y. W. (2017). "Monitoring of microbial communities in anaerobic digestion sludge for biogas optimisation," Waste Management 71, 344-341. DOI: 10.1016/j.wasman.2017.10.007 
Maroušek, J. (2014)."Significant breakthrough in biochar cost reduction," Clean Technol. Envir. 16(8), 1821-1825. DOI: 10.1007/s10098-014-0730-y

Maroušek, J., Hašková, S., Zeman, R., Váchal, J., and Vaníčková, R. (2014). "Nutrient management in processing of steam-exploded lignocellulose phytomass," Chem. Engineer. Technol. 37(1), 1945-1948. DOI:10.1002/ceat.201400341

Maroušek, J., and Kwan, J. T. H. (2013). "Use of pressure manifestations following the water plasma expansion for phytomass disintegration," Water Sci. Technol. 67(1) 1695-1700. DOI: 10.2166/wst.2013.041

Mhedbi-Hajri, N., Jacques, M.-A., and Koebnik, R. (2011). "Adhesion mechanisms of plant-pathogenic Xanthomonadaceae, in: Bacterial Adhesion, Chemistry, Biology and Physics, D. Linke, A. Goldman (eds.), Springer, Dordrecht, Netherlands.

Montusiewicz, A., and Lebiocka, M. (2011). "Co-digestion of intermediate landfill leachate and sewage sludge as a method of leachate utilization," Bioresource Technol. 102(3), 2563-2571. DOI: 10.1016/j.biortech.2010.11.105

Munk, B., Guebitz, G. M., and Lebuhn, M. (2017). "Influence of nitrogen-rich substrates on biogas production and on the methanogenic community under mesophilic and thermophilic conditions," Anaerobe 46, 146-154. DOI: 10.1016/j.anaerobe.2017.02.015

Naushad, S., Adeolu, M., Wong, S., Sohail, M., Schellhorn, H. E., and Gupta, R. S., (2015). "A phylogenomic and molecular marker based taxonomic framework for the order Xanthomonadales: proposal to transfer the families Algiphilaceae and Solimonadaceae to the order Nevskiales ord. nov. and to create a new family within the order Xanthomonadales, the family Rhodanobacteraceae fam. nov., containing the genus Rhodanobacter and its closest relatives," Antonie Van Leeuwenhoek 107(2), 467-485. DOI: 10.1007/s10482-014-0344-8

Oleszek, M., Tys, J., Wiącek, D., Król, A., and Kuna, J. (2016). "The possibility of meeting greenhouse energy and $\mathrm{CO}_{2}$ demands through utilisation of cucumber and tomato residues," Bioenerg. Resources 9(2), 624-632. DOI: 10.1007/s12155-0159705-Z

Ondov, B. D., Bergman, N.H., and Phillippy, A.M. (2011). "Interactive metagenomic visualization in a web browser," BMC Bioinformatics 12, 385.

Oszust, K., Panek, J., Pertile, G., Siczek, A., Oleszek, M., and Frąc, M. (2018). "Metabolic and genetic properties of Petriella setifera precultured on waste," Front. Microbiol. 9, 115 DOI:10.3389/fmicb.2018.00115

Oszust, K., Frąc, M., and Lipiec, J. (2015). "Soil microbial functionality in response to dairy sewage sludge and mineral fertilisers application under winter rape," Int. J. Env. Sci. Technol. 12(11), 3675-3684. DOI: 10.1007/s13762-015-0807-0

Oszust, K., Pawlik, A., Janusz, G., Ziemiński, K., Cyran, M., Siczek, A., Gryta, A., Bilińska-Wielgus, N., and Frąc, M. (2017). "Characterization and influence of a multi-enzymatic biopreparation for biogas yield enhancement," BioResources 12(3), 6187-6206. DOI: 10.15376/biores.12.3.6187-6206

Pascual, J., Von Hoermann, C., Rottler-Hoermann, A. M., Nevo, O., Geppert, A., Sikorski, J., Huber, K. J., Steiger, S., Ayasse, M., and Overmann, J. (2017). "Function of bacterial community dynamics in the formation of cadaveric semiochemicals during in situ carcass decomposition," Env. Microbiol. 19(8), 3310-3322. DOI: 10.1111/1462-2920.13828

Perrotta, A. R., Kumaraswamy, R., Bastidas-Oyanedel, J. R., Alm, E. J., and Rodríguez, J. (2017). "Inoculum composition determines microbial community and function in 
an anaerobic sequential batch reactor," PLOS One 12, e0171369. DOI:

10.1371/journal.pone.0171369

Shivaji, S., Srinivas, T. N. R., and Reddy, G. S. N. (2014). "The family Planococcaceae," in: The Prokaryotes: Firmicutes and Tenericutes E. Rosenberg, E. F. DeLong, S. Lory, E.Stackebrandt, F. Thompson (eds), Springer Berlin Heidelberg, Berlin, Heidelberg, pp. 303-351. DOI: 10.1007/978-3-642-30120-9_351

Schink, B., Montag, D., Keller, A., and Müller, N. (2017). "Hydrogen or formate, alternative key players in methanogenic degradation," Env. Microbiol. Rep. 9(3), 189202.

Su, P., Lou, J., Brookes, P. C., Luo, Y., He, Y., and Xu, J. (2017). "Taxon-specific responses of soil microbial communities to different soil priming effects induced by addition of plant residues and their biochars," J. Soil Sediment 17(3), 674-684. DOI: 10.1007/s 11368-015-1238-8

Szarlip, P., Stelmach, W., Jaromin-Gleń, K., Bieganowski, A., Brzezińska, M., Trembaczowski, A., Hałas, S., and Łagód, G. (2014). "Comparison of the dynamics of natural biodegradation of petrol and diesel oil in soil," Desalin. Water Treat. 52, 3690-3697

Van Nguyen, Q., Jensen, L. S., Bol, R., Wu, D., Triolo, J. M., Vazifehkhoran, A. H., and Bruun, S. (2017). "Biogas digester hydraulic retention time affects oxygen consumption patterns and greenhouse gas emissions after application of digestate to soil," J. Environ. Qual. 46(5), 1114-1122. DOI: 10.2134/jeq2017.03.0117

Vanwonterghem, I., Jensen, P. D., Ho, D. P., Batstone, D. J., and Tyson, G. W. (2014). "Linking microbial community structure, interactions and function in anaerobic digesters using new molecular techniques," Curr. Opin. Biotech. 27, 55-64. DOI: 10.1016/j.copbio.2013.11.004

Veeken, A., and Hamelers, B. (1999). "Effect of temperature on hydrolysis rates of selected biowaste components," Bioresource Technol. 69(3), 249-254. DOI: 10.1016/S0960-8524(98)00188-6

Větrovský, T., and Baldrian, P. (2013). "The variability of the 16S rRNA gene in bacterial genomes and its consequences for bacterial community analyses," PLoS One 8:e57923. DOI:10.1371/journal.pone.0057923

Vochozka, M., and Maroušková, A. (2017). "Valuation of fermentation residues from biogas stations," Energy Sources, Part A: Recovery, Utilization, and Environmental Effects 39, 905-910. DOI: 10.1080/15567036.2016.1273282

Wang, X., Lu, X., Li, F., and Yang, G. (2014). "Effects of temperature and carbonnitrogen $(\mathrm{C} / \mathrm{N})$ ratio on the performance of anaerobic co-digestion of dairy manure, chicken manure and rice straw, focusing on ammonia inhibition," PLOS One 9, e97265. DOI: 10.1371/journal.pone.0097265

Westerholm, M., Isaksson, S., Sun, L., and Schnürer, A. (2017). "Microbial community ability to adapt to altered temperature conditions influences operating stability in anaerobic digestion," Energy Procedia 105, 895-900. DOI: 10.1016/j.egypro.2017.03.408

Wyman, C. E., Dale B. E., Elander, R. T., Holtzapple, M., Ladisch, M. R., and Lee, Y. Y. (2005). "Coordinated development of leading biomass pretreatment technologies," Bioresource Technol. 96(1), 1959-1966. DOI: 10.1016/j.biortech.2005.01.010

Yu, X.-J., and Walker, D. H. (2006). "The order Rickettsiales", in: The Prokaryotes, Vol. 5, Proteobacteria, Alpha and Beta Subclasses, M. Dworkin, S. Falkow, E. Rosenberg, K.-H. Schleifer, and E. Stackebrandt (eds.), Springer, New York, NY. 
Zhang, P., Zeng, G., Zhang, G., Li, Y., Zhang, B., and Fan, M. (2008). "Anaerobic codigestion of biosolids and organic fraction of municipal solid waste by sequencing batch process," Fuel Process. Technol. 89(4), 485-489. DOI: 10.1016/j.fuproc.2007.11.013

Zheng, Y., Pan, Z., and Zhang, R. (2009). "Overview of biomass pretreatment for cellulosic ethanol production," Int. J. Agr. Biol. Eng. 2(3), 51. DOI: 10.3965/j.issn.1934-6344.2009.03.051-068

Zhao, C., Mu, H., Zhao, Y., Wang, L., and Zuo, B. (2017). "Microbial characteristics analysis and kinetic studies on substrate composition to methane after microbial and nutritional regulation of fruit and vegetable wastes anaerobic digestion," Bioresource Technol. 249, 315-321. DOI: 10.1016/j.biortech.2017.10.041.

Article submitted: February 16, 2018; Peer review completed: May 5, 2018; Revised version received: and accepted: May 25, 2018; Published: June 11, 2018.

DOI: 10.15376/biores.13.3.5740-5764 